\section{Health in All Policies and the Sustainable Development}

\section{Abstract}

This text approaches the interaction between the Health in All Policies (HiAP) agenda and the ongoing implementation of the 2030 Agenda for Sustainable Development. The HiAP applies similar integrated issues related to the Sustainable Development framework (economic, social, and environmental development). On the other hand, the HiAP approach can contribute to the Sustainable Development Goals (SDGs) implementation. The author proposes that both initiatives could be coordinated contributing to the implementation of both processes.

Keywords: Agenda 2030; Sustainable development goals; Health policies; Social determinants of health; Equity in health

\section{Luis Eduardo Fonseca}

Researcher, Oswaldo Cruz Foundation, Fiocruz Center for Global Health, Av . Brazil , 4365, Rio de Janeiro, 21040-360, Brazil

\section{Corresponding author: Fonseca LE}

\section{luiz.eduardo@fiocruz.br}

Researcher, Oswaldo Cruz Foundation, Fiocruz Center for Global Health, Av. Brazil, 4365, Rio de Janeiro, 21040-360, Brazil.

\section{Tel: 55-21-991319544}

Citation: Fonseca LE. Health in All Policies and the Sustainable Development. Health Syst Policy Res. 2016, 3:3.

\section{Background}

The Ministerial Declaration of the World Conference on the Social Determinants of Health [1], held in Rio de Janeiro, 2011, advocated Health in All Policies as a valuable mechanism to promote health equity and build accountability for health into policies in other sectors. The approach was further legitimized by the Declaration of the $8^{\text {th }}$ Global Conference of Health Promotion, which recognized multi-sectoral action and health-oriented public policy as "central elements for the promotion of health, the achievement of health equity, and the realization of health as a human right" [2]. In September 2014, the Ministers of Health of the Region of the Americas approved the Regional Plan of Action on HiAP [3], calling attention to the consequences and benefits for health of policies and actions developed by other sectors.

Sustainable Development Goal 3 of the 2030 Agenda 3, "to ensure healthy life and promote well-being for all at all ages", sets out nine targets and four means of implementation. Three of the targets of SDG 3 incorporate those of the Millennium Development Goals (MDGs). The other six targets refer to noncommunicable diseases, mental health and well-being (target 4); substance abuse (target 5); traffic accidents (target 6); sexual and reproductive health (target 7 ); universal health coverage, including access to healthcare services, medicines and vaccines (target 8); and public health and environment (target 9).

Of course, this set of targets is not sufficient to implement the entirety of SDG 3. It is clear that contributions from sectors outside of health will be instrumental in achieving progress. In other words, the SDGs are an indivisible and interdependent set of goals for sustainable development. Employing this broader approach to understanding health progress and deterioration will allow for a more flexible and effective multi-sectoral approach, which I believe respect to the HiAP. In this sense, effective coordination between the the implementation of the 2030 Agenda and the HiAP can make an important contribution to the positioning of health in the wider development agenda

\section{Health in All Policies as an Inter-linkage Mechanism}

Health in All Policies (HiAP) is an approach that can link the goals, means and priorities associated with health in the SDGs to those of other policies. This concept was first addressed at the Alma Ata International Conference on Primary Health Care [4] and at several Conferences on Health Promotion: Ottawa [5], Adelaide [6], Bogotá [7], and in the Caribbean Charter for Health Promotion [8]. These Conferences important documents were revisited on a global level in the final document of the WHO Commission on Social Determinants of Health [9] (WHO), in the Adelaide Statement on Health in All Policies [10], at the WHO World Conference on Social Determinants of Health [11] (Rio de Janeiro, 2011), and followed by the $8^{\text {th }}$ Global Conference on Health Promotion [12], where the core subject was Health in All Policies, leading to a Declaration [13] and a framework for HiAP actions at the country level [14].

In the PAHO Strategic Plan 2014-2019, the widely accepted concept of HiAP was described as "an approach to public policies across sectors that systematically takes into account the health 
implications of decisions, seeks synergies, and avoids harmful health impacts in order to improve population health and health equity".

While the HiAP concept involves synergy between health promotion, social determinants of health, and human rights, substantial synergy similarly exists between HiAP and SDG implementation. HiAP is an approach aimed at the participation of the health sector in the broad process of intersectoral governance, and is ideally suited for addressing SDH manifested in other SDGs. It is vital to optimize the implementation of SDGs that are relevant to achieve health, and reduce harm caused by other policies on health.

Moreover, greater efforts are needed in order to pursue and strengthen the integration of the SDGs and the HiAP agenda. These include identifying priority issues that can affect different sectors at different levels, developing monitoring systems to incorporate $\mathrm{HiAP/SDG}$-sensitive indicators, improving the evidence base for approaches to intersectoral collaboration, mapping and developing thematic websites, training for HiAP and SDG policy decision-makers, and activities designed to train trainers.

It is clear that achieving progress in SDG 3 calls for action to be coordinated with the targets aimed at by other SDGs. HiAP can answer to this, but its most effective approach at the national level will depend on the dimensions of local government policies. To the governance of the process the same importance can be ascribed to institutional and managerial arrangements, as well as to the development of appropriate technical tools and mechanisms to ensure that policy guidance and coordination effectively materialize [14]. Concepts and practices of a Situational Strategic Planning applied to the intersectoral dimension can also be extremely valuable in this respect. The central goal should be to define processes that will enable the success of national development plans, aligned with the 2030 Sustainable Development Agenda and facilitated by the Health in All Policies approach. 


\section{References}

1 (2011) World Health Organization: World Conference on Social Determinants of Health, Rio de Janeiro.

2 (2013) World Health Organization: Eighth International Conference on Health Promotion. Helsinki, Finland.

3 (2014) Pan American Health Organization/ World Health Organization: Plan of Action on HiAP. $53^{\text {rd }}$ Directing Council. $66^{\text {th }}$ Session of the Regional Committee of WHO for the Americas.

4 (1978) Declaration of Alma Ata International Conference on Primary Health Care, Alma Ata, USSR.

5 (1986) World Health Organization: First International Conference on Health Promotion. The Ottawa Charter for Health Promotion, Geneva.

6 (1988) World Health Organization: Second International Conference on Health Promotion, Adelaide, South Australia.
7 (1992) IUHPE World Conference on Health Promotion. Santa Fé de Bogotá, Colombia.

8 (1993) First Caribbean Conference of Health Promotion.

9 (2010) World Health Organization: Commission on Social Determinants of Health.

10 (2009) World Health Organization: Adelaide Statement on Health in All Policies.

11 (2011) World Health Organization: World Conference on Social Determinants of Health, Rio de Janeiro.

12 (2013) World Health Organization: Eighth International Conference on Health Promotion. Helsinki, Finland.

13 (2019) PAHO. PAHO Strategic Plan 2014-2019.

14 Máttar J, Perroti DE (2014) Planificación, prospectiva y gestión pública: Reflexiones para la agenda del desarrollo. 